\title{
O Deus do progresso: a difusão do cientificismo no movimento operário gaúcho da I República*
}

Benito Bisso Schmidt Universidade Federal do Rio Grande do Sul

RESUMO

O objetivo do artigo é examinar a difusão de teorias cientificistas no movimento operário gaúcho no período da I República, tais como o positivismo, o darwinismo, a antropologia criminal, o espiritismo kardecista, etc.; bem como os canais de difusão de tais idéias e suas repercussões políticas, sobretudo a conformação de um "estilo autoritário" na condução das lutas operárias.

Palavras-chave: cientificismo; movimento operário; autoritarismo.

\begin{abstract}
This article aims at examining the diffusion of scientism theories in the gaúcho working movement in the 1st Republic, such as darwinism, criminal anthropology, the kardecist spiritism etc.; as well as the channels of diffusion of such ideas and its political repercution, above all else the conformation of an "authoritarian style" in the conduction of the working struggle. Keywords: scientism; working movement; authoritarianism.
\end{abstract}

\section{"Não me apregoem sistemas completos, não me [enfileirem conquistas \\ Das ciências (das ciências, Deus meu, das ciências!) Das ciências, das artes, da civilização moderna!”}

Fernando Pessoa

Os últimos anos do século XIX e os primeiros do XX foram marcados pela difusão de diversas teorias cientificistas que deixaram marcas profundas no estudo da natureza (com o evolucionismo de Darwin) e da sociedade (com o positivismo de Comte e o darwinismo social de Spencer), no direito e na psiquiatria (com a antropologia criminal de Cesare Lombroso e Enrico Ferri) e mesmo na religião (com o kardecismo). Tais correntes procuravam romper com as explicações abstratas e metafísicas, 
buscando desvendar racionalmente a lógica do mundo natural, social, humano e sobrenatural, preferencialmente através da observação empírica. Todas tinham como ponto em comum a convicção de que a ciência e a técnica poderiam resolver os problemas básicos da humanidade. Idéias como estas encontraram ampla acolhida no Brasil, sobretudo entre os grupos urbanos. Afinal, para diversos setores da elite política e intelectual nativa, nosso jovem país precisava seguir, após a abolição da escravidão e a proclamação da República, os rumos do "progresso" e da "civilização" sinalizados pela Europa.

Muitas das lideranças da classe operária emergente no país, inspiradas no exemplo de seus pares europeus, também adotaram e difundiram as concepções antes mencionadas. Neste sentido, por exemplo, Batalha comenta que o termo marxismo é aqui empregado em fins do século XIX como sinônimo de socialismo científico ou socialismo positivo. Seixas, na mesma linha, afirma que o caráter teórico dominante presente na genealogia do socialismo e do anarquismo em São Paulo e no Rio de Janeiro é tributário da cultura positivista européia do século passadon. Ambos os autores ressaltam, porém, a impropriedade de se perceber tal assimilação como um "exotismo brasileiro", um caso de "idéias fora do lugar" ou um sintoma do "porre ideológico" de nossos militantes; pelo contrá114 rio, tal mélange estaria presente na própria matriz européia do socialismo (seja ele marxista ou anarquista) naquele contexto. Assim, não se pode esquecer a influência do positivismo no pensamento da Segunda Internacional socialista e, do lado anarquista, o cientificismo e o evolucionismo de um Kropotkine ou de um Elisée Reclus.

Quando se examina a documentação referente ao movimento operário gaúcho no período em questão é possível identificar claramente a presença dessas idéias. Afinal, em um contexto em que a crença no progresso e nos poderes ilimitados da ciência era hegemônica, muitos militantes, das mais diversas correntes ideológicas, procuraram interpretar a realidade local e justificar suas concepções políticas a partir de "critérios científicos". O objetivo do presente artigo é examinar a formação e a difusão de uma cultura cientificista no movimento operário do Rio Grande do Sul durante a República Velha, analisando: algumas teorias científicas que circulavam neste movimento; os canais de difusão das mesmas e suas repercussões políticas.

Quanto às idéias cientificistas assimiladas, é possível perceber a predominância do positivismo, o que provavelmente se deve a dois fatores: o destaque que esta doutrina tinha no movimento operário internacio- 
nal, sobretudo no âmbito da social-democracia, e sua importância na vida política e social rio-grandense naquele momento. De acordo com Löwy, na época da Segunda Internacional, "pode-se observar a presença ideológica das diferentes variantes do positivismo (...) não somente nas correntes chamadas 'revisionistas' mas no seio do próprio 'marxismo ortodoxo"'. Entre os socialistas neopositivistas, o autor destaca os italianos Enrico Ferri e Filipo Turati. Este último, por exemplo, escreveu em 1884 que se alegrava pelo fato de o socialismo tomar uma característica "mais e mais científica, mais e mais positiva" ${ }^{2}$.

Embora entre os anarquistas a penetração do positivismo fosse menor, ela não deve ser negligenciada. O pensamento de Kropotkine ilustra bem a medida desta influência: "Nosso método é o das ciências naturais exatas (...). Por isso trabalhamos para construir nossa filosofia científica (...) de forma a englobar toda a natureza e todos os efeitos de ordem social em uma mesma unidade de idéias - sem, no entanto, cair nos excessos de Auguste Comte e de Herbert Spencer em suas tentativas do mesmo gênero" ${ }^{3}$. No Rio Grande do Sul, assim como nas demais regiões do país, o movimento operário bebeu desta fonte teórica européia. Em decorrência, as concepções positivistas também integraram o cardápio doutrinário de nossos militantes.

Além disso, é preciso assinalar igualmente que o pensamento de Comte, com suas variações, penetrou na realidade gaúcha por outros caminhos, sobretudo pela ação do Partido Republicano Rio-Grandense (PRR). Tal partido, hegemônico no Rio Grande do Sul ao longo da I República, tinha como base doutrinária uma versão própria do positivismo, o castilhismo (por alusão ao presidente do Estado Júlio de Castilhos), que foi institucionalizado através da Constituição Estadual de 1891. Além desta vertente política, as concepções de Comte difundiram-se por diversos níveis da sociedade local, sobretudo entre os intelectuais, mas também na vida cotidiana. Sobre este ponto, Boeira interroga-se:

Como classificar a publicação do calendário positivista ao lado do calendário gregoriano, nos almanaques do começo do século? Ou a referência ao "busto de Augusto Comte" no folclore e ao 'tal de positivismo' nos poemas regionalistas? O que dizer da "Farmácia da Humanidade" e da "Lavanderia Ordem e Progresso"? E das referências ao positivismo nos versos de poetas diletantes do interior e nas charges humorísticas? E do intendente inculto do interior que, falando da instrução em seu municí- 
pio, refere-se também à "idéia fixa do progresso" que permitirá a todos serem lutadores "no campo de honra em prol da Humanidade"?4.

Com tais considerações, quero ressaltar a contaminação da sociedade gaúcha pelo positivismo ou, para ser mais preciso, com idéias e imagens tributárias desta corrente, a qual o movimento operário não ficou imune.

Assim, por exemplo, o militante socialista Antônio Guedes Coutinho, que atuou na cidade de Rio Grande na virada do século XIX, afirmou em 1900 não conhecer as obras do "genial pensador [Comte] senão por resumos muito insuficientes (...)”. Porém declarou em diversos momentos assentar seu pensamento "(...) na lógica dos fatos e de acordo com os princípios filosóficos da ciência positiva (...)”. Além disso, embora reconhecesse o teor burguês dessa teoria, não deixava de admirar seus adeptos: "Decididamente a escola de Comte tem muitos grandes homens e é inegável que são eles os únicos que merecem confiança ao povo, dentro do sistema burguês." Em outro momento, chegou a afirmar que o pensador francês “(...) concebeu um sistema sociológico que hoje mesmo ainda é seguido pelos próprios socialistas científicos como meio de transi116 ção para o coletivismo"; e acrescentou: "o socialismo (...) nada mais é do que o sistema de Comte (...) reformado e ampliado de acordo com os progressos da humanidade" ${ }^{5}$.

A concepção do positivismo como etapa de transição para o socialismo parece ter tido uma vigência longa no Rio Grande do Sul, para além dos limites temporais propostos a este artigo. Um exemplo: o escritor e psiquiatra Dyonélio Machado, presidente estadual da ANL em 1935 e constituinte estadual pelo PCB em 1946, na prisão em Porto Alegre por ter organizado uma greve dos gráficos da Livraria do Globo em 1937, recebeu a visita do antigo líder republicano Paim Filho. Ao comentar sua situação, disse ao amigo:

- Devo isto aos senhores.

Os senhores eram Borges de Medeiros, Protásio Alves, Paim Filho.

- Como?...

- Os senhores me iniciaram, claro que indiretamente, no socialismo.

Socialismo de estado, positivista. Progredi: fui até o socialismo propriamente dito: o socialismo marxista. ${ }^{6}$

Levando adiante esta linha de raciocínio, o gaúcho Getúlio Vargas, embora referindo-se a um contexto diferente, também reforça em seu Diá- 
rio a aproximação do socialismo com o positivismo: “(...) esse general [Gal. Manuel Rabelo Mendes - RJ, 1878-1945] é um tanto responsável pela rebelião dos corpos da sua região. Gosta de dar entrevistas com uns conceitos e atitudes que inquietam e perturbam. Positivista, seu positivismo é interpretado de um modo que estabelece certa consagüinidade com o comunismo" 7 .

Qual seria a consagüinidade do socialismo/marxismo/comunismo com as concepções positivistas? Em primeiro lugar, ambas as correntes buscam uma sustentação racional e científica para a forma como interpretam a realidade e para suas propostas de transformação social. Outros traços comuns a elas são a perspectiva evolucionista (das formas inferiores às formas superiores de organização da sociedade) e a crítica ao individualismo burguês.

Contudo, além destas afinidades teóricas, é preciso considerar que o positivismo era a grande moda intelectual da época, ao qual todas as teorias que se pretendessem científicas (leia-se "verdadeiras" ou "corretas") deveriam ajustar-se. Não é à toa que o mesmo Coutinho referido anteriormente considerava $O$ Capital de Marx como um "colossal monumento da ciência (...)" e acreditava que o socialismo era orientado pelas "leis científicas da história" ${ }^{8}$.

Porém, a admiração pelo positivismo não era consensual entre os militantes socialistas gaúchos. Em outras fontes, encontram-se críticas a esta doutrina, sobretudo à sua instrumentalização pelo PRR. Assim, o Manifesto do Partido Operário ao operariado do Rio Grande do Sul, de 1905, afirmava ironicamente:

Estabelecida na terra gaúcha a doutrina comtista como orientação governamental, e em absoluta negação ao que pregavam no tempo da monarquia os propagandistas republicanos rio-grandenses, nós, os proletários, ficamos oficialmente reconhecidos como párias e tanto assim é que, de quando em quando em tentativas de aparente interesse por nossa sorte, aventa-se aqui, em conciliábulos filosóficos daquela doutrina, a comiserativa idéia de 'nos incorporar à sociedade'.

No jornal A Democracia, porta-voz dos socialistas porto-alegrenses, um articulista chamava Comte de "genial velho maluco" e criticava os positivistas por serem "vaidosos e incoerentes" e viverem "às expensas do erário público" ". Percebe-se, portanto, que as críticas eram dirigidas mais ao governo gaúcho, e aos seus representantes, do que à teoria comtiana propriamente dita. Como os socialistas tinham como um de seus alvos 
principais os poderes constituídos e a sociedade capitalista, o positivismo também era atacado por ser o alicerce ideológico da "política burguesa” local.

Outras correntes cientificistas também foram incorporadas pelos líderes do movimento operário gaúcho; entre elas destacam-se o evolucionismo, o darwinismo social, a antropologia criminial e o espiritismo kardecista. Charles Darwin, no seu Origem das espécies (1859), formulou uma explicação detalhada e fartamente documentada da forma e do processo da evolução através da seleção natural ou da preservação das raças favorecidas na luta pela vida. Herbert Spencer, por seu turno, defendeu a aplicação da teoria evolucionista a todos os campos do conhecimento, inclusive na análise da sociedade. Esta concepção é conhecida como darwinismo social.

No âmbito da criminologia, os italianos (e socialistas) Cesare Lombroso e Enrico Ferri, entre outros, tentaram implantar uma visão científica do crime. Por esta, seria possível descobrir, através de determinadas características físicas, as tendências criminosas dos homicidas antes mesmo que cometessem algum delito. Já Allan Kardec procurou unir racionalismo e crença, buscando associar os novos métodos da ciência aos enigmas metafísicos a fim de explicar racionalmente o mundo espiritual e a imortalidade.

Uma citação do militante Coutinho ilustra bem a influência do darwinismo nos meios socialistas gaúchos: “o socialismo não só não é contrário à lei da luta pela vida, como veio justificá-la em face da ciência e da economia política”. Contudo, segundo ele, no sistema capitalista, esta "lei imutável e invencível” adquiria um caráter "egoísta” e "deprimente”, pois não revertia em benefício da coletividade, mas exclusivamente de alguns poucos indivíduos: "que nos importa o trabalho dum capitalista que trabalha num projeto onde o seu capital individual se possa centuplicar?". A luta pela vida precisava ser "digna, em abono do indivíduo e da coletividade: que os homens lutem mas que trabalhem em alguma coisa de interesse coletivo".

Idéia semelhante pode ser encontrada em um exemplar de 1902 do jornal significativamente intitulado $A$ Evolução, orgam semanal dedicado às classes caixeral e operária, de Bagé:

Evoluir... esse o 'mot d'ordre' que hoje escapa de todos os lábios e que as inanimadas coisas parecem ecoar. Tudo evoluiu, tudo se agita em luta ciclópica, gigante, para alcançar uma coisa melhor, apenas em sonho entrevista, em mórbidos sonhos acarinhadas (...). Que a desigualdade é a lei da 
natureza e a igualdade absoluta uma utopia - nós bem o sabemos. Mas a solução do problema social não consiste em estabelecer a igualdade absoluta, sim, em organizar a sociedade de modo a oferecer e facilitar a cada um dos meios de poder desenvolver livremente as suas capacidades, sem prejudicar uns aos outros. ${ }^{10}$

Em alguns textos publicados na imprensa operária rio-grandense, a concepção evolucionista aparece mediada pela antropologia criminal: “(...) nós estamos com (...) Ferri, Lombroso, etc., que vêem nas teorias de Darwin o mais perfeito caminho para o socialismo". No jornal socialista A Democracia, as teorias lombrosianas são usadas como instrumento de crítica ao anarquismo. Assim, Elisée Reclus é chamado de gênio “(...) e, por isto mesmo, segundo C. Lombroso, mais ou menos desequilibrado (...)" ${ }^{\text {"11 }}$ Quanto ao kardecismo, é possível encontrar diversos militantes seguidores, ou ao menos simpatizantes, desta doutrina: os socialistas Coutinho e Carlos Cavaco, os anarquistas Stefan Michalski e Espertirina Martins $^{12}$ e Abílio de Nequete, um dos fundadores do PCB. O primeiro afirmava que o espiritismo era uma "ciência da alma”, pois a própria “(...) ciência (...), com as suas mil formas de análise e observação, está hoje afirmando a existência do espírito que sobrevive à matéria, e provado isto, o resto da Doutrina impõe-se como conseqüência lógica da perfeição universal”. Cavaco valeu-se de uma argumentação semelhante para justificar sua adesão ao kardecismo: "hoje, felizmente, o espiritismo entrou no domínio das ciências respeitadas, estudadas" ${ }^{13}$. Nequete, por seu turno, chegou a formular uma doutrina espírita própria, o "evidentismo”, "espiritismo sem religiosidade nem charlatanismo". Neste sentido, ao saber da vitória de Lênin na Rússia, afirmou: "estava achado o campo de ação que o espiritismo, degenerado em preces e consagrante da propriedade individual, não me facultava... O espiritismo serviu-me de escola e o bolchevismo de oficina" ${ }^{14}$. Ou seja, mesmo no campo espiritual, os líderes operários citados buscavam comprovar o teor científico de suas idéias.

Os exemplos dados até aqui referem-se quase exclusivamente à difusão das teorias cientificistas no âmbito da social-democracia onde, sem dúvida, esta foi mais acentuada. Contudo, também nos escritos produzidos pelos anarquistas é possível encontrar passagens reveladoras da valorização da ciência e da razão. No jornal libertário A Luta, por exemplo, pode-se ler uma justificativa científica para o anticlericalismo:

A religião é uma enfermidade

Assim o demonstra o dr. Binet-Sanglé, professor da Escola de Psico- 
logia, de Paris, em uma notável série de estudos fisiológicos subordinados à epígrafe: 'As leis psicofisiológicas do desenvolvimento das religiões'.

A religião tem como condição primeira a fé, que suprime a razão.

Dahi o crente carecendo de equilíbrio intelectual, é uma victima assinalada para todas as sugestões.

Já nos Estatutos da Sociedade Pró-Ensino Racionalista de Porto Alegre, com orientação anarquista, proclama-se igualmente que a mesma "propagará, por todos os meios, a adoção do ensino racionalista e científico" ${ }^{15}$.

Feito este breve inventário das correntes cientificistas que circulavam no movimento operário gaúcho na I República, cabe investigar os canais por onde se dava tal circulação, dos quais destacarei três: a circulação de livros, jornais e folhetos; as bibliotecas e as escolas. O já citado Antônio Guedes Coutinho, por exemplo, parece ter tomado contato com estas teorias, ou aprimorado seu conhecimento das mesmas, através do material bibliográfico que lhe era enviado pelo socialista e criminologista argentino José Ingegnieros, principal divulgador das propostas de Lombroso na 120 América Latina, com quem mantinha uma assídua correspondência. Foi por intermédio deste último que chegou às suas mãos a edição argentina da obra Socialismo e Sciencia Positiva. Darwin-Spencer-Marx de Ferri. Coutinho traduziu o texto do espanhol e publicou-o como folhetim no jornal que dirigia, o Echo Operário. Em uma nota, salientou a importância da obra, destacando que "o seu autor é um dos mais célebres criminalistas italianos, sociólogo eminente e deputado ao parlamento italiano" ${ }^{16}$. Esta troca de material doutrinário parece ter sido freqüente no período em questão. Em relação à imprensa, por exemplo, Petersen assinala que “(...) era intensa a circulação dos jornais operários (...) além dos próprios assinantes, os jornais eram enviados às redações dos 'co-irmãos', às associações operárias e outras entidades não necessariamente operárias como bibliotecas públicas, clubes recreativos e musicais, etc." ${ }^{17}$.

Quanto aos livros e folhetos, muitas vezes os próprios redatores dos periódicos encarregavam-se de promover sua divulgação. Nestes jornais, era comum a existência de colunas de livros recebidos ou que poderiam ser encomendados. Por exemplo, o Echo Operário noticiou em 1898: "nosso ilustrado colega e companheiro José Ingegnieros (...), atendendo à falta de livros que há aqui para propagar o socialismo, presenteou-nos, o que muito agradecemos, com um pacote de diversos folhetos". O anarquista $A$ Luta, por 
sua vez, informou em 1908 ter recebido o folheto 0 militarismo ante a politica moderna, publicado e enviado pelo Apostolado Positivista da capital, no qual se condenava a guerra e o armamentismo ${ }^{18}$. As bibliotecas também eram um meio privilegiado para a circulação destas idéias. Na biblioteca da Sociedade União Operária de Rio Grande, uma das poucas, senão a única do Estado que foi preservada, pode-se encontrar os seguintes títulos, entre outros semelhantes: 0 darwinismo e a guerra de P. Chalmers Mitchell; A questão da vacina, de Joaquim Bagueira Leal, publicado pela Igreja Positivista do Brasil, e o Catecismo positivista, de Comte. Por fim, as escolas fundadas pelos operários, sobretudo pelos anarquistas, também podem ter contribuído para a difusão das concepções cientificistas. Em Porto Alegre, por exemplo, funcionaram algumas, como a Escola Moderna e a Escola Elisée Reclus. Sobre a concepção pedagógica que embasava tais estabelecimentos, são significativas as palavras de Maurício de Medeiros, publicadas na Revista Liberal de 1921:

O ensino racionalista não está filiado a seita alguma de ordem social ou religiosa. É um método de ensino, método em toda a acepção da palavra; o conjunto de meios os mais curtos e mais seguros para chegar à verdade. Ninguém dirá hoje, por exemplo, que o método experimental, generalizado em ciência, pertença a qualquer facção, das que estudam os problemas sociais, pelo fato de suas aquisições derribarem velhas concepções por esta ou por aquela facção defendidas.

Tudo evolui, tudo caminha. O próprio homem de hoje é inteiramente diverso; o ambiente em que ele vive é inteiramente outro: - porque conservar rotineiramente os mesmos processos de desenvolver-lhe a inteligência?

Polidoro Santos, militante anarquista destacado no movimento operário gaúcho, também defendia a necessidade de uma escola racionalista, pois, segundo ele, "um estabelecimento de instrução e educação racionalista seria o núcleo de onde poderia irradiar, abrangendo a cidade depois o Estado, quiçá o país, os princípios de uma educação racional e lógica, correspondendo aos nossos tempos e preparando a mocidade para enfrentar resolutamente a luta pela vida”. Para tanto, era necessária “(...) a edição de obras didáticas, calcadas sob os princípios de uma pedagogia racional e científica (...)" ${ }^{\prime 19}$.

O último ponto que gostaria de abordar neste artigo diz respeito à influência que as idéias cientificistas tiveram na atuação das lideranças do movimento operário rio-grandense. No âmbito da social-democracia, 
embora seja possível encontrar eventualmente discursos revolucionários, verifica-se a predominância de práticas que buscavam uma reforma gradativa da sociedade burguesa existente: a organização de associações operárias objetivando a conquista de benefícios para os trabalhadores (jornada de 8 horas, tribunais de arbítrio para resolver as contendas entre patrões e empregados, etc.); a formação de um partido socialista visando à conquista do poder político e uma série de medidas para promover a "elevação cultural do proletariado" (escolas, bibliotecas, imprensa, teatro, etc.).

Este gradualismo, inspirado pelo Partido Social Democrata alemão e pelas idéias de pensadores como o francês Benoît Malon, era justificado através das teorias evolucionistas. Por exemplo, o militante socialista Coutinho afirmou em 1898: "Não (...) desejamos por meio da dinamite ou nitroglicerina arrasar o que há para construir de novo, mas sim aplicando às leis evolutivas, que auxiliaremos com a ciência, reformas transitórias para pouco a pouco conseguirmos a transformação.” Em 1901 sua posição não era diferente: "sabemos que a natureza não dá saltos e que será pela evolução que hão de fazer-se as grandes reformas necessárias à transformação econômica dos povos" ${ }^{20}$. Ou seja, assim como, segundo Darwin, a natureza não se modifica aos saltos, também a sociedade deveria evoluir lentamente até a forma mais perfeita de organização: o socialismo.

Uma outra possível influência das idéias cientificistas na atuação dos líderes operários gaúchos diz respeito à conformação do que se poderia chamar de um "estilo autoritário" na condução do movimento. Este, para usar as palavras de Stoppino, supõe, entre outras coisas, "a disposição à arrogância e ao desprezo dos inferiores hierárquicos e, em geral, de todos os que estejam privados de força ou de poder" ${ }^{21}$.

No caso em questão, a "força e o poder" relacionam-se com o conhecimento das teorias sociais científicas, o que conferiria a alguns o direito de dirigir o conjunto dos trabalhadores. O nosso já bem conhecido Coutinho é também exemplar neste sentido. Para ele, o operariado deveria "(...) ouvir a palavra amiga e verdadeira dos companheiros mais educados (...)”. Em outro momento afirmou “(...) julgamos necessária a direção das massas por aqueles que forem capazes de dirigi-las”. Ou ainda: "o povo quer por enquanto quem o dirija (...)"22.

Entre os anarquistas também vigorava uma prática política pedagógica voltada para as classes operárias em formação, com a finalidade de orientá-las, sendo que esta seria promovida não por indivíduos isoladamente mas pelos sindicatos. Neste sentido, as palavras de Cornelissen, publicadas na Revista Liberal, são significativas: "Os sindicatos operários, que nós consideramos os grupos diretores (orientadores) da luta de classes, não podem ser, antes de tudo, senão organização (sic) de luta (resis- 
tência) (...)". A mesma revista proclamava como seu objetivo “(...) auxiliar essa evolução do povo elevando-lhe o nível moral e intelectual (...)”23.

O "desprezo pelos inferiores hierárquicos", ou seja, pelo conjunto dos operários, é bem evidente na atuação do comunista Abílio de Nequete. Ao ser convidado em 1943 para um comício dos funcionários da fábrica Renner, respondeu que "os operários não valiam nada" pois, apesar dos protestos, ficavam muito felizes quando ganhavam cestas de Natal dos seus patrões ${ }^{24}$. Em virtude desta postura, elaborou uma doutrina própria, a tecnocracia, que preconizava um governo de técnicos, "minoria culta", e não de operários, "maioria inculta, desconfiada e de fácil intriga" 25 .

Finalmente quero assinalar que a influência das teorias cientificistas, sobretudo do positivismo, parece ter contribuído para a adesão de alguns dos mais destacados líderes socialistas e comunistas - mas não dos anarquistas, entre os quais a influência desta doutrina era menor, pelo menos segundo as fontes consultadas - do Estado ao PRR e, no pós-30, ao governo trabalhista de Vargas, oriundo das fileiras do PRR, e que também bebeu dos ensinamentos positivistas. Segundo Boeira, o único postulado comtiano importante do programa castilhista que persistiu, e até mesmo cresceu de importância na prática do PRR, ao longo de toda a sua trajetória, foi o da incorporação do proletariado à sociedade moderna ${ }^{26}$.

Do lado dos operários, verifica-se, na conjuntura de 1906-1912, uma aproximação das lideranças da social-democracia ao partido governista e, posteriormente, sua adesão ao trabalhismo. Citarei alguns fatos para comprovar essa afirmação. Em 1911, o socialista Antonio Heit, proprietário do jornal Echo do Povo, dirigiu uma carta aberta ao chefe do PRR Borges de Medeiros, solicitando "(...) que a classe trabalhadora, do nosso querido Rio Grande do Sul, seja, também, contemplada com um representante na próxima eleição para a Assembléia Estadual". Dizia ainda: "Não cogito quem seja o escolhido; ouso pedir, unicamente, que, a escolha que V. Ex. fizer, recaia em pessoa competente, tirada do seio do operariado, conhecedora das necessidades da classe, e que, na banca do trabalho, sinta o quanto é penosa a existência dos que com o suor do seu rosto precisam ganhar o pão quotidiano para si e sua família." ${ }^{27}$

Tal aspiração concretizou-se parcialmente um ano depois quando o litógrafo Francisco Xavier da Costa, o grande articulador do movimento socialista em Porto Alegre, foi eleito pelo PRR para o Conselho Municipal, permanecendo no cargo, com algumas interrupções, até 1930. Com o fechamento deste órgão, passou a integrar o Conselho Consultivo do Estado e, no ano seguinte, fundou o Conselho Consultivo dos Trabalha- 
dores da Capital, composto por um representante de cada associação operária, visando à unificação do proletariado metropolitano. "Iremos à terra da promissão de que fala Karl Marx - à emancipação da classe operária”, disse ele na instalação da entidade ${ }^{28}$.

Carlos Cavaco, outro militante socialista gaúcho muito ativo durante a República Velha, editou, com Lindolfo Collor, o jornal Correio da Tarde em 1910. Em 1930 apoiou a ascensão de Vargas ao poder. Apesar disso, foi preso um ano depois em Fortaleza, quando participava de uma reunião com os operários da Legião Cearence do Trabalho, por declararse socialista revolucionário. Contudo, este incidente não o afastou da política oficial do pós-30. Pelo contrário, a partir de então ocupou diversos cargos públicos, principalmente no Ministério do Trabalho. Em 1953 foi nomeado pelo ministro do trabalho João Goulart para o cargo de assessor técnico da Comissão de Orientação Sindical ${ }^{29}$. Antônio Guedes Coutinho, por seu turno, concedeu uma entrevista ao jornal 0 Tempo em 1940, na qual era qualificado como "veterano defensor dos ideais trabalhistas". Nela afirmava:

O socialismo faliu. O pensamento humano evoluiu.

Brilhante demonstração desta afirmativa é a política sábia e superiormente orientada pelo presidente Vargas, eminente fundador do Estado Novo, que deu ao trabalhador brasileiro, espontaneamente, sem lutas, sem estremecimentos ameaçadores da estrutura das nossas instituições básicas, tudo, ou mais do que aquilo que violentamente pensávamos conseguir ${ }^{30}$.

Já Nequete, de acordo com seu filho Lenine, tinha uma admiração pelos personagens fortes e autoritários como Alexandre Magno, Júlio Cesar, Júlio de Castilhos e Borges de Medeiros, e chegou a escrever para o jornal A Federação, órgão oficial do PRR. Afirmou também que o pai era anti-getulista, mas que aprovou a medida de Getúlio de fechar o Partido Integralista, pois era sobretudo anti-integralista.

Tais exemplos, recolhidos de modo indiciário e ainda sujeitos a uma análise mais rigorosa, sugerem a hipótese de que, entre os trabalhadores, Vargas não foi sustentado apenas pelos pelegos, mas também por lideranças históricas do movimento operário gaúcho. Uma das explicações para o fato talvez seja a existência de um caldo de cultura positivista comum a socialistas e trabalhistas.

Para concluir, espero ter demonstrado que o movimento operário gaúcho da I República, apesar da sua diversidade ideológica, foi perpassado por um viés cientificista comum, embora com repercussões diferenciadas entre socialistas e anarquistas. Afinal, essa era uma época em que 
a ciência parecia ser, de acordo com as palavras de Coutinho, o "deus do progresso"...

\section{NOTAS}

* Agradeço aos colegas Adhemar Lourenço da Silva Jr., Alexandre Fortes, Evangelia Aravanis e Luiz Alberto Grijó, pelas informações e indicações de fontes; e a Luís Cláudio Molina Pinto pela tradução do resumo. Este trabalho contou com o auxílio da FAPERGS.

${ }^{1}$ BATALHA, Claudio H. M. "A difusão do marxismo e os socialistas brasileiros na virada do século XIX”. In: MORAES, João Quartim de (org.). História do marxismo no Brasil II: os influxos teóricos. Campinas, Ed. da UnICAMP, 1995. p. 12, e SEIXAS, Jacy Alves de. "Anarquismo e socialismo no Brasil: as fontes positivistas e darwinistas sociais". História \& Perspectivas, Uberlândia, (12/13): pp. 133-148, jan./dez. 1995. Sobre o tema, ver também: PANSARDI, Marcos Vinícius. "O socialismo dos modernos e o socialismo dos antigos: a incorporação do vocabulário ideológico da II Internacional pelo movimento socialista brasileiro.” História social: revista da Pós-Graduação em História. Campinas, IFCH/UNICAMP, nº 1, 1994. ${ }^{2}$ Löwy, Michael. As aventuras de Karl Marx contra o Barão de Münchbausen: marxismo e positivismo na sociologia do conhecimento. São Paulo: Busca Vida, 1987. p. 110. A citação de Turati foi retirada deste livro, p. 113.

${ }^{3}$ Apud SeIXAS, Jacy A. de. "Anarquismo e socialismo no Brasil...", op. cit.

${ }^{4}$ Boeira, Nelson. "O Rio Grande de Augusto Comte”. In: Dacanal, José Hildebrando e GonZAGA, Sergius (orgs.). RS: cultura \& ideologia. Porto Alegre, Mercado Aberto, 1980, p. 54.

${ }^{5}$ O Artista. Rio Grande, 10/3/1900. p. 1; ECHO OperÁrIO. Rio Grande, 13/3/1898. p. 1 e 29/10/1899. pp. 2-3 e O ARTISTA. 10/3/1900, p. 1, respectivamente.

${ }^{6}$ Machado, Dyonélio. Memórias de um pobre homem. Porto Alegre: IEL, 1990, pp. 81-82.

${ }^{7}$ VARGAS, Getúlio. Diário. Rio de Janeiro: Siciliano/FGV, 1995, v. I, p. 466.

${ }^{8}$ Echo Operário. Rio Grande, 26/9/1897, p. 1, e O Tempo. Rio Grande, 23/5/1907, p. 1 , respectivamente.

${ }^{9}$ A DEMOCRACIA. Porto Alegre, 1/5/1905, pp. $2-3$ e 15/10/1905, p. 1, respectivamente.

${ }^{10}$ ECho Operário. Rio Grande, 26/9/1897, p. 1 e A Evolução. Bagé, 2/2/1902, p. 1.

${ }^{11}$ Echo Operário. Rio Grande, 28/8/1898, p. 1 e A Democracia. Porto Alegre, 28/2/1907, p. 1, respectivamente.

${ }^{12}$ Ver SILVA JR., Adhemar Lourenço da. "Povo! Trabalhadores!": tumultos e movimento operário (estudo centrado em Porto Alegre, 1917). Porto Alegre: PPG em História da UFRGS, 1994 (dissertação de mestrado). p. 255, nota 108.

${ }^{13}$ A Regeneração. Rio Grande, 1/4/1901, pp. 1-2 e Petit Journal. Porto Alegre, 21/6/1906, p. 2, respectivamente.

${ }^{14}$ Apud Rosito, Renata Irene Haas. O pensamento político de Abilio de Nequete. Porto Alegre: Curso de Bacharelado em Ciências Sociais da PUC/RS, 1972.

${ }^{15}$ A LuTA. Porto Alegre, 1/5/1910, p. 2 e Sociedade Pró-Ensino Racionalista - Estatutos. Porto Alegre, 1916. Apud: Petersen, Sílvia R. F., e LuCAS, Maria E. Antologia do movimento 
operário gaúcho, 1870-1937. Porto Alegre: Ed. da Universidade/UFRGS - Tchê!, 1992, p. 189.

${ }^{16} \mathrm{O}$ envio desta obra foi noticiado pelo ECHO OperáRIO. Rio Grande, 18/1/1898, p. 4. No "Manifesto" do Partido Socialista Brasileiro publicado no O ESTADO DE S. PAulo, em 28 de agosto de 1902, o livro de Ferri é incluído entre os "livros mais recommendaveis para o estudo do socialismo scientifico". A nota de Coutinho aparece em FERRI, Enrique. Socialismo e sciencia positiva. Darwin-Spencer-Marx. Rio Grande, 1898 (publicado como folhetim no "Echo Operário"), p. 4.

${ }^{17}$ Petersen, Sílvia R. F. "Cruzando fronteiras: as pesquisas regionais e a história operária brasileira”. Anos 90: revista do Programa de Pós-Graduação em História da UFRGS. Porto Alegre, $\mathrm{n}^{0} 3$, maio de 1995, p. 145.

${ }^{18}$ Echo Operário. Rio Grande, 18/1/1898, p. 4 e A LuTA. Porto Alegre, 9/2/1908, respectivamente.

${ }^{19}$ Medeiros, Maurício. “O ensino racionalista”. Revista Liberal. Porto Alegre, outubro de 1921, e SANTOS, Polidoro. "Uma escola racionalista em Porto Alegre: necessidade premente.” Revista Liberal. Porto Alegre, outubro de 1921. Apud Petersen, Sílvia R. F. e LuCAS, Maria Elizabeth. “Antologia...”, op. cit., pp. 270-271.

${ }^{20}$ Echo Operário. Rio Grande, 31/10/1897, p. 1, e 1/5/1901, p. 1, respectivamente.

${ }^{21}$ Stoppino, Mario. Verbete "autoritarismo". In: BobBio, Norberto, e MatTeucci, Nicola (dir.). Diccionario de política. México: Siglo XXI, 1995, p. 143.

${ }^{22}$ CoutinHo, Antônio Guedes. Catecismo socialista. Rio Grande, 1898 (publicado como folhetim no "Echo Operário"), p. 4; ECHO OPERÁRIO. Rio Grande, 23/1/1898, p. 3 e 25/9/1898, p. 1, respectivamente.

${ }^{23}$ CORNELISSEN, Ch[ristian]. "Os operários em marcha". Revista Liberal. Porto Alegre, julho de 1921. Apud SILVA JR., Adhemar Lourenço da. "Povo! Trabalhadores!...”, op. cit., p. 14 (grifo meu), e Revista Liberal. Porto Alegre, fevereiro de 1921. Apud Petersen, Sílvia R. F., e LUCAS, Maria Elizabeth. “Antologia...”, op. cit., p. 259.

${ }^{24}$ Segundo depoimento de seu filho, Lenine de Nequete, ao autor. Porto Alegre, 30/1/1997.

${ }^{25}$ Apud ROSITO, Renata Irene H. "O pensamento político de Abilio de Nequete”, op. cit.

${ }^{26}$ Boeira, Nelson. "O Rio Grande...”, op. cit., p. 44.

${ }^{27}$ Echo do Povo. Porto Alegre, 12/10/1911, p. 1. Apud Petersen, Sílvia R. F., e Lucas, Maria Elizabeth. “Antologia...”, op. cit., p. 161.

${ }^{28}$ MARÇAL, João Batista. "Francisco Xavier da Costa, patriarca do socialismo no RGS". A Luta. Órgão oficial do Partido Socialista Brasileiro — Rio Grande do Sul. Porto Alegre, $\mathrm{n}^{0} 46$, junho de 1996, p. 5.

${ }^{29}$ Dados retirados de CAGGIANI, Ivo. Carlos Cavaco: a vida quixotesca do tribuno popular de Porto Alegre. Porto Alegre: Martins Liveiro, 1986.

${ }^{30} \mathrm{O}$ Tempo. Rio Grande, 22/5/1940, p. 1. (grifo meu). 